NOTAS 



\title{
RICARDO SENABRE SEMPERE (1937-2015) Y LA CRÍTICA LITERARIA ESPAÑOLA
}

\author{
Francisco AbAd NeBOT \\ UNED \\ fabad@flog.uned.es
}

La historia de la crítica literaria española en la Edad Contemporánea se halla por hacer; absolutamente nadie - y lo decimos también por nosotros - se ha encontrado con fuerzas para trazarla, a manera de continuación de la Historia de las ideas estéticas en España de Menéndez Pelayo. Desde Alberto Lista o Bartolomé José Gallardo a 1950 van transcurridas doce generaciones de españoles y otras tantas de estudiosos de la literatura; uno de ellos ha sido Ricardo Senabre, nacido en la más reciente de tales hornadas que consideramos, la de quienes vinieron al mundo entre 1936 y 1950: Senabre era de los mayores del conjunto. Los autores venidos al mundo desde 1921 y 1935, más los que acabamos de apuntar, se hallan en parte vivos; los que han nacido tras 1951 se encuentran haciendo aún su obra -a veces muy incipientemente-, por lo que no cabe referirse aún a ellos.

Existe una costumbre no escrita que es la de - al hacer inventarios de cualquier tarea intelectual o profesional- excluir de ellos a los autores vivos; tal hecho no se ha seguido en el capítulo final del volumen 8, "Ideas literarias: siglos XIII a XX", de la Historia de la literatura española de la Ed. Crítica; así se lo hemos manifestado de manera sencilla y con cordialidad al autor de ese capítulo: si se habla de los principiantes, y de los colegas, se corre el riesgo de llegar a un resultado muy sesgado y hasta en ocasiones un tanto caótico según hemos oído decir a un lector del aludido capítulo, en el que además se hace alusión de manera asimismo muy parcial al mundo sesgadísimo de las oposiciones y concursos.

Las generaciones españolas en las que encontramos a nuestros estudiosos de la literatura son (se indica el espacio respectivo de fechas de nacimiento):1771-1785 (Gallardo); 17861800 (Pedro José Pidal; Gil y Zárate); 1801-1815 (Larra; Rivadeneyra); 1816-1830 (Milá; José Amador de los Ríos); 1831-1845 (Giner de los Ríos; Francisco de Paula Canalejas); 1846-1860 (Menéndez Pelayo; Clarín); 1861-1875 (Menéndez Pidal; Andrenio) —es ya la generación del 98-; 1876-1890 (Ortega; Américo Castro; Federico de Onís); 1891-1905 (los estudiosos del Veintisiete); 1906-1920 (Alborg; J. A. Maravall; Blecua; Lapesa; Riquer; V. 
Llorens); 1921-1935 (José María Valverde; Antonio Vilanova); 1936-1950 (J. M. Rozas; R. Senabre; Ignacio Prat).

$* * *$

Ricardo Senabre nació en Alcoy el 30 de Noviembre de 1937. Se incorpora a la Universidad cuando cursa en la de Zaragoza los que se denominaban "cursos comunes" en la Facultad de Filosofía y Letras.

En tales estudios comunes —que el eminente medievalista José Ángel García de Cortázar y algún profesor más han pedido que se restablezcan - fue alumno de don Eugenio Frutos.

Frutos era - lo he declarado muchas veces- (escribe Senabre), el mejor profesor que he tenido en mi vida. [...] Sin un papel, sin una nota, con un discurso de una fluidez y una claridad insuperables. [...] En aquellos años - 1955,1956 - la enseñanza de la filosofía en las Universidades españolas se reducía casi exclusivamente a un merodeo en torno al tomismo. En los lugares donde se llegaba un poco más lejos, lo más moderno era Descartes. En cambio Frutos nos hablaba del existencialismo - palabra casi vitanda entonces—-, de Jaspers, de Heiddeger y de JeanPaul Sartre ( qque entonces figuraba en el índice de libros prohibidos!), de tal manera que uno salía de allí dispuesto a buscar como fuese las obras de estos autores y devorarlas lo antes posible.

Sin duda la aludida claridad y fluidez de este maestro resultó un estímulo imborrable para su entonces alumno, quien debido a sus propias capacidades muestra asimismo en sus escritos la misma fluidez en la construcción del discurso y análoga claridad, no muy frecuente en la logomaquia de la crítica usual en varias artes (entre nosotros se da hasta un programa de radio que lee fragmentos de crítica de arte a modo de censura de lo ininteligible que se acostumbra a veces).

Digamos también al paso que por los mismos años de la docencia de Frutos, el luego crítico de cine, ensayista y novelista Luciano G[onzález] Egido fue expulsado del profesorado de la Universidad de Salamanca debido a haber recomendado una obra de Sartre para el análisis; quien lo expulsó fue el rector falangista Antonio Tovar; intervino en el asunto incluso el Obispo de la ciudad: en el aludido contexto resalta aún más la figura de Frutos.

Los cursos de la especialidad los estudió Ricardo Senabre en la Universidad de Salamanca, y a la ciudad salmantina unió de por vida su paso por este mundo, aunque con un amplio paréntesis de tres lustros en que desarrolló su tarea intelectual y de gestión en Cáceres, etapa que el propio profesor tenía por "imborrable" y que en su percepción "llenó la parte central de [su] vida", entre -en números redondos- sus treinta y cuatro y los cuarenta y ocho años. La obra de gestión fue muy amplia, aunque no dejó de estudiar y escribir por eso: era una persona llena de fuerza y de vitalidad, y atento a la actualidad.

Acabada la licenciatura de "Filología Románica" en Salamanca fue profesor en la Facultad de Filosofía y Letras en que había estudiado; se doctoró con una excelente tesis sobre la lengua y el estilo de Ortega y Gasset y tras las oposiciones y concursos correspondientes, quedó en tanto catedrático de la materia entonces denominada "Gramática General y Crítica Literaria”. Un nuevo concurso de traslado a fines del curso 1985-1986 lo llevó a su cátedra definitiva de la Universidad de Salamanca. 
Para el otoño de 1985 la titulación doble a la que aludimos se había desdoblado en dos escalafones cada uno de una materia, llamados entonces de "Lingüística General" y de "Crítica Literaria" y más adelante "Teoría de la Literatura", y el prof. Senabre eligió el segundo, esto es, el que le llevaba a materias literarias.

En la primera posguerra se había creado en efecto la disciplina académica a que aludimos de "Gramática General y Crítica Literaria"; se convocó una plaza de ella en la entonces llamada Universidad Central, y uno de los firmantes fue Rafael Lapesa, quien presentó como obligatorio "trabajo de firma" de cátedra (para ser admitido a la oposición), la monografía que al poco se transformó en un libro perdurable: La trayectoria poética de Garcilaso. Para dar salida administrativa a Lapesa y no tener que competir con él -hemos oído relatar en diversas ocasiones-, se dotó con rapidez otra plaza de "Gramática histórica de la lengua española" que fue en definitiva a la que accedió don Rafael. Quienes ganaron la guerra civil expedientaron a Lapesa por haber trabajado durante las fases iniciales de la contienda en la tarea de salvación del patrimonio histórico y cultural en los locales del "Centro de Estudios Históricos" de Medinaceli, 4, de Madrid: lo acusaron de contribuir a aparentar la normalidad de la vida bajo el gobierno de Negrín.

Pero prestigio cierto debía de poseer el Lapesa de cuarenta años cuando —en la práctica - se le dotó una plaza que iba a allanar también en la práctica la carrera académica de otras personas. Ricardo Senabre mantuvo siempre respeto a don Rafael; en sucesivas ocasiones hablábamos de él, y yo le transmitía varios de los contenidos que tenían los últimos cursos de su vida (de la vida de Lapesa) en el Colegio Libre de Eméritos o - más ocasionalmente- en la Fundación Juan March (lecciones estás últimas que pueden oírse porque se hallan guardadas en la página web de la Fundación).

La cátedra de "Gramática General y Crítica Literaria” que se dotó en la Universidad de Salamanca y que iba a ocupar en su día R. Senabre fue ganada la vez primera por el prof. Fernando Lázaro Carreter, quien se mantuvo en tal plaza durante veinte años un poco largos; con posterioridad se trasladó a ella desde Granada el prof. Antonio Llorente Maldonado de Guevara, mas este profesor — cuando la legalidad vigente se lo permitió— pasó a la titulación de "Lengua Española”: él se dedicaba en realidad a la dialectología de la lengua patrimonial, y no se dedicó nunca a la "Crítica literaria" que formaba parte de su titulación, ni de hecho a la "Linguiística General”, pues lo que publicó al respecto procedía de los materiales que hubo de preparar para opositar. Sólo unos meses permaneció en esa plaza un tercer profesor, que al quedar nuevamente vacante ocupó en la parte literaria —ya desdoblada por tanto— Ricardo Senabre.

En una evocación salmantino-vallisoletana puedo decir que la referencia a escritores vinculados a Salamanca como Fray Luis, Unamuno, o Luciano G. Egido, a los profs. Lázaro y Senabre, y a autores vallisoletanos como Jorge Guillén y José Jiménez Lozano, que tal referencia — digo - puede formar parte de una de las zonas de la vida psicológica e intelectual interior de quienes han pasado por esas ciudades, independientemente de que se coincida o no con unos u otros aspectos de la personalidad respectiva de los autores mencionados, o de que ellos coincidiesen con la de los demás.

Ricardo Senabre padecía una dolencia pulmonar crónica desde hace quizá un par de lustros, y a resultas de esa dolencia ha muerto en Alicante este muy desdichado y aún reciente 
5 de Febrero de 2015. ¡Terrible mes de Febrero en estos años!: un día 1 murió Lapesa; ahora un 5 de Febrero el prof. Senabre ya no está entre nosotros ni con nosotros; un día 8 me decía el propio Ricardo por teléfono (lo que había sabido a través de la prensa digital), que había muerto mi colega de Facultad en su día Javier Tusell.

$$
* * *
$$

Senabre era un profesor muy responsable y muy vocacional, en el marco de la vocación esencial de su vida: la lectura de los textos literarios; de esta manera dirigió bastantes tesis doctorales, y consta cómo en ocasiones catedráticos de la especialidad filológica o de otras materias escuchaban con agrado sus exposiciones orales. Las tesis — si formaba parte de un tribunal— las llevaba siempre muy leídas y anotadas.

La obra escrita de este profesor desaparecido se extiende a lo largo de casi sesenta años, y de esta manera se ha escrito con razón cómo "en él confluyeron las facetas de investigador y filólogo, de teórico de la literatura y de crítico literario, que desplegó con una prodigiosa intensidad, hasta lo ingente".

Su primera obra extensa fue lógicamente la de su buena tesis de doctorado (Lengua y estilo de Ortega y Gasset); estamos ante una monografía innovadora en su momento y que ha servido de punto de partida de otras más análogas en el método. El autor promovió tal modelo de estudio entre sus discípulos, y se cuenta así con varias monografías referidas al idioma artístico de autores de los siglos XIX y primer tercio del XX, en realidad de los años de la Edad de Plata (1868-1936); alguna otra tesis se remonta a tiempos literarios más antiguos. Vinieron luego tres obras más breves dedicadas a Rafael Alberti, a Fray Luis de León, y a Gracián; la segunda de ellas apareció una segunda vez ampliada con otros capítulos. Todos los presentes textos estuvieron publicados por la Universidad salmantina, y procedieron en general de cursos monográficos impartidos oralmente.

Para quien ha estado vinculado a ciudades como Zaragoza o Salamanca no es fácil dejar de ocuparse de Fray Luis y de Gracián; R. Senabre lo ha hecho con claridad de juicio y con análisis en detalle de la elocución fónica.

Cuando trata de El Criticón se reafirma en una idea - y la ilustra- que ha sido apuntada en varias ocasiones: la de que esta que por comodidad llamaremos novela de Gracián constituye la ejemplificación de su propia Agudeza y arte de ingenio. Gracián escribe nuestro autor,

seguro ya de su misión como escritor, realiza algo insólito en la historia literaria: escribir una obra que, a la vez que se apoya en otra suya anterior [...], le sirve también de demostración. Ninguno de los poetas y escritores de los que Gracián extrae sus ejemplos para la Agudeza ofrece [...] modelos para todos los casos inventariados. El Criticón en cambio sí, y esta circunstancia [... convierte] El Criticón en la summa de la poética barroca.

No obstante el cotejo completo y riguroso entre las dos obras mencionadas se halla aún por hacer. 
$* * *$

Un texto unitario de Senabre resultó el de Literatura y público, como asimismo resultaron unitarios asimismo los libros (de una u otra amplitud) Antonio Machado y Juan Ramón Jiménez poetas del siglo Xx; y Metáfora y novela; este último revela al lector gustoso e inteligente del género.

En volúmenes extensos ha reunido el autor parte de sus monografías específicas: han surgido así los volúmenes Capítulos de historia de la lengua literaria y Claves de la poesía española contemporánea: de Bécquer a Brines. Estamos ante dos obras en verdad mayores: la primera contiene sucesivas muestras de Historia del idioma artístico español, idioma sólo atendido en parte de manera general, y olvidado — se diría que programáticamente- en varias exposiciones recientes de la trayectoria del idioma.

R. Senabre era consciente de lo que puede llamarse la quiebra de la filología entre nosotros, y sabía también lo abandonado que se halla el siglo XIX en los análisis lingüísticos: se propuso así y propuso a sus alumnos dedicarse la lengua literaria de la última parte del Ochocientos y el primer tercio del xx.

***

Un escrito acaso poco conocido de nuestro autor es el de la primero conferencia y luego folleto La demolición de la enseñanza (2012); transcribimos algunas de sus percepciones y afirmaciones:

1. "Una enseñanza defectuosa obtura por completo las posibilidades de un progreso social adecuado a los tiempos venideros".

2. "El aprendizaje de cualquier técnica debería ir precedido por un sustrato de conocimientos generales que constituyera la base cultural imprescindible sobre la que asentar todo lo demás". En efecto si la especialización resulta prematura, se corre el riesgo — que los hechos demuestran — de caer en errores incluso bastante elementales.

3. "La realidad es tozuda": una persona o un colectivo pueden sesgar, silenciar, etc., la percepción de datos de la realidad, pero los datos siguen existiendo, forman parte de lo real.

4. "La lectura es siempre una ampliación del mundo personal".

5. Las humanidades "sirven para formar seres pensantes, no absortos en su única y exclusiva especialidad ni ensimismados [...]. Pueden ser capaces de analizar actitudes, de descifrar discursos y comportamientos y compararlos con los de otros tiempos y lugares. [...] Serán cualquier cosa menos ciudadanos dóciles”.

6. "Suprimidas las antiguas oposiciones, que [...] en conjunto permitían dar una imagen muy clara de su preparación a quienes participaban en ellas, se han ido creando otros sistemas [...] siempre encaminados a facilitar el ingreso", sin necesidad de ver ni oúr físicamente al solicitante. 
7. "La trivialidad, cuando no la ignorancia oceánica, ha ido implantándose en el ámbito universitario y ocupando un espacio, quizá todavía mínimo, pero expansivo". Nuestra experiencia nos dice que los aludidos desconocimientos no cabe referirlos sólo a profesores jóvenes especializados desde el inicio, sino a profesores que por la edad han tenido tiempo sobrado para leer y estudiar lo que en ocasiones no pasan de elementalidades.

Etc.

***

¿En qué se caracteriza la obra críticoliteraria de Ricardo Senabre en el conjunto de la de otros estudiosos? Podemos enunciar algunos rasgos, a saber:

a) La tarea inicial es la de una lectura en detalle y tomando anotaciones del texto de que se trate. Leer resulta lo más gustoso para él.

b) Sus análisis se hallan más dirigidos hacia las formas literarias que hacia los contenidos connotados de historia, historia de las mentalidades, etc. Es una opción formalista - en el mejor sentido- acerca de la obra artística.

c) Estamos ante una Crítica que da gran importancia al componente fónico del lenguaje, tal como con él se logra un artificio estético en las obras.

d) Distingue a los escritos del autor una gran claridad y nitidez expresivas: resultan fáciles de leer y entender. El uso de terminologías o jergas neologistas es muy medido.

e) En ocasiones R. Senabre ha escrito monografías unitarias; en otras artículos más breves que esas monografías, y que han encontrado su pertinencia orgánica en varias recopilaciones

\section{$* * *$}

El prof. Ricardo Senabre era un estudioso con prestigio de autoridad por su claridad en la elocución y agudeza; sobre todo era un filólogo, según decimos. Estuvo vinculado a la Facultad de Filología de la UNED, en la que impartió lecciones y formó parte de tribunales de oposiciones y de tribunales de tesis: prestó así un honrado y buen servicio. Nos hizo el honor de aceptar formar parte del Comité asesor de EPOS.

Descanse en paz, y sirva de modelo su trabajo profesional. 